NENAD SAULIĆ, M.Sc. ${ }^{1}$

(Corresponding author)

E-mail: nenadsaulic@gmail.com,n.saulic@uns.ac.rs

ZORAN PAPIĆ, Ph.D. ${ }^{1}$

E-mail: njele@uns.ac rs

ZORAN OVCIN, Ph.D. ${ }^{1}$

E-mail: zovcin@uns.ac.rs

${ }^{1}$ University of Novi Sad

Faculty of Technical Sciences

Trg Dositeja Obradovića 6, 21000 Novi Sad, Serbia
Safety and Security in Traffic Original Scientific Paper

Submitted: 12 July 2019

Accepted: 19 Feb. 2020

\title{
PEDESTRIAN THROW DISTANCE PREDICTION FROM VEHICLE DAMAGE INTENSITY
}

\begin{abstract}
One of the main points to be addressed when analysing vehicle-pedestrian collisions is the vehicle impact speed. If the traffic accident is not recorded on camera, and there are no skid marks nor tachograph in the vehicle, the parameter is determined on the basis of empirical models. All empirical models for ascertaining vehicle speed are based on the pedestrian throw distance, which is not always known because of an unidentified vehicle-pedestrian collision point or the final rest position of the pedestrian after collision. This paper shows a description of a vehicle damage recorded in an ordinal scale and determines the pedestrian throw distance prediction model from the vehicle damage established in such a way. If the accident scene is documented by photographs, the damage can be classified, and by applying a validated model, the pedestrian throw distance envisaged. Then, by applying an empirical model, one can determine the speed of the vehicle at the time of collision with a pedestrian. Two databases were formed during the research. The first is based on real-life traffic accidents (expert witnessing of the professors from the Faculty of Technical Sciences). The second is based on traffic accident simulations as part of PC Crash software package.
\end{abstract}

\section{KEY WORDS}

pedestrian traffic accidents; throw distance; vehicle damage; vehicle speed;

\section{INTRODUCTION}

Vehicle-pedestrian collision inevitably leaves marks on both, the pedestrian's body, in the form of injuries, and on the vehicles, in the form of cosmetic or structural damage. The analysis of both marks is of paramount importance in determining the circumstances under which the accident occurred. It is vital to establish the pedestrian injuries in correlation with the vehicle damages. The analysis of pedestrian injuries and vehicle damages helps answer the basic questions which arise in the traffic accident analysis. The pedestrians do not have external protection and are therefore exposed to a direct contact with the oncoming vehicle. As a result, this group of road users is considered the most vulnerable group, along with the cyclists and motorcyclists. Due to the considerable difference in the masses of participants (vehicle-pedestrian), traffic accidents involving pedestrians, in almost all cases have resulted in injuries to pedestrians [1]. When a traffic accident occurs, the job of the transportation-technology expert witness is to determine the circumstances under which the event occurred. The vehicle speed at the point of collision with a pedestrian is one of the parameters which need to be established during the reconstruction of events and in determining the circumstances of the accident. The points which determine the vehicle speed are: skid marks, point of impact (glass splinters, paint flakes, etc.), pedestrian body position after the accident, vehicle damage, pedestrian injuries and heights, pedestrian movement, etc. Currently, there are more empirical mathematical models which can determine the vehicle impact speed. Limpert [2] established a model which can obtain the vehicle impact speed from pedestrian throw distance and the vehicle deceleration factor. Searle [3], Stcherbatcheff [4] and Wood and Simms $[5,6]$ established models for calculation of forward vehicle speed that take into account only one independent parameter - pedestrian throw distance. Besides pedestrian throw distance, Eubanks [7] includes additional independent elements in the vehicle speed calculation model. Table 1 shows the previously mentioned and some other authors of the empirical formulae which are being used among experts worldwide. Moreover, the table also shows 
parameters one should be familiar with in order to apply the same mathematical models. As seen in Table 1, all empirical formulae for speed calculation are based on pedestrian throw distance which gives a particular meaning to this parameter.

Namely, to know the throw distance parameter, it is necessary to determine the point of contact between the vehicle and the pedestrian, and the position of the body after the accident (Figure 1). It becomes a problem when these data cannot be determined, i.e. when the point of contact between the vehicle and the pedestrian is questionable (no material evidence which would indicate the position), or when the final rest position of the pedestrian after the accident is unknown (pedestrian taken to hospital to receive treatment, got up and moved independently, etc.). Therefore, all of the above empirical formulae for determination of the forward vehicle speed cannot be used. If there is no braking, no skidding marks at the accident scene, or if there are no video surveillance cameras nearby, or if the tachograph card is not taken from the vehicle (contact involves a vehicle that has a tachograph), the vehicle speed can only be assumed [13]. In these types of situations, the transportation-technology expert witnesses cannot determine this, nor many other circumstances of traffic accidents, with certainty.

Table 1 - Parameters required for application of empirical formulae when determining the vehicle impact speed [2, 8-12]

\begin{tabular}{|c|c|c|c|c|c|c|c|c|c|c|c|}
\hline \multirow[b]{2}{*}{ Authors } & \multicolumn{11}{|c|}{ Parameters } \\
\hline & 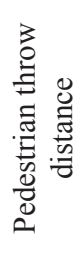 & 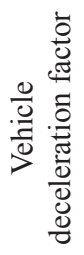 & 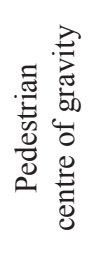 & 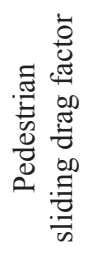 & 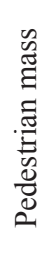 & $\begin{array}{l}0 \\
0 \\
\text { ปे } \\
0 \\
0 \\
0 \\
0 \\
0\end{array}$ & 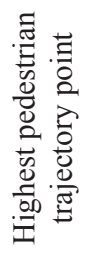 & 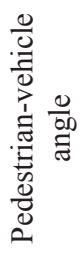 & 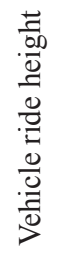 & 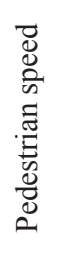 & 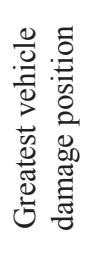 \\
\hline $\begin{array}{l}\text { Aronberg } \\
\text { \& Snider }\end{array}$ & $\mathrm{X}$ & & & $\mathrm{X}$ & & & $\mathrm{X}$ & $\mathrm{X}$ & & & \\
\hline $\begin{array}{l}\text { Barzeley } \\
\& \text { Lacy }\end{array}$ & $\mathrm{X}$ & & & & & & & & & & \\
\hline Casteel & $\mathrm{X}$ & & $\mathrm{X}$ & & & & & & $\mathrm{X}$ & & \\
\hline Collins & $\mathrm{X}$ & & $\mathrm{X}$ & $\mathrm{X}$ & & & & & & & \\
\hline Eubanks & $\mathrm{X}$ & $X$ & $\mathrm{X}$ & & & & & $\mathrm{X}$ & $\mathrm{X}$ & $\mathrm{X}$ & $\mathrm{X}$ \\
\hline $\begin{array}{l}\text { Eubanks } \\
\& \text { dr. Bank }\end{array}$ & $\mathrm{X}$ & & $\mathrm{X}$ & $\mathrm{X}$ & & & & & & & \\
\hline Limpert & $\mathrm{X}$ & $\mathrm{X}$ & & & & & & & & & \\
\hline Pultar & $\mathrm{X}$ & & $\mathrm{X}$ & & & & & & & & \\
\hline Searle & $\mathrm{X}$ & & & $\mathrm{X}$ & & & & & & & \\
\hline Stcherbatcheff & $\mathrm{X}$ & & & $\mathrm{X}$ & & & & & & & \\
\hline Wood & $\mathrm{X}$ & & $\mathrm{X}$ & $\mathrm{X}$ & $\mathrm{X}$ & $\mathrm{X}$ & & & & & \\
\hline Wood & $\mathrm{X}$ & & & & & & & & & & \\
\hline
\end{tabular}

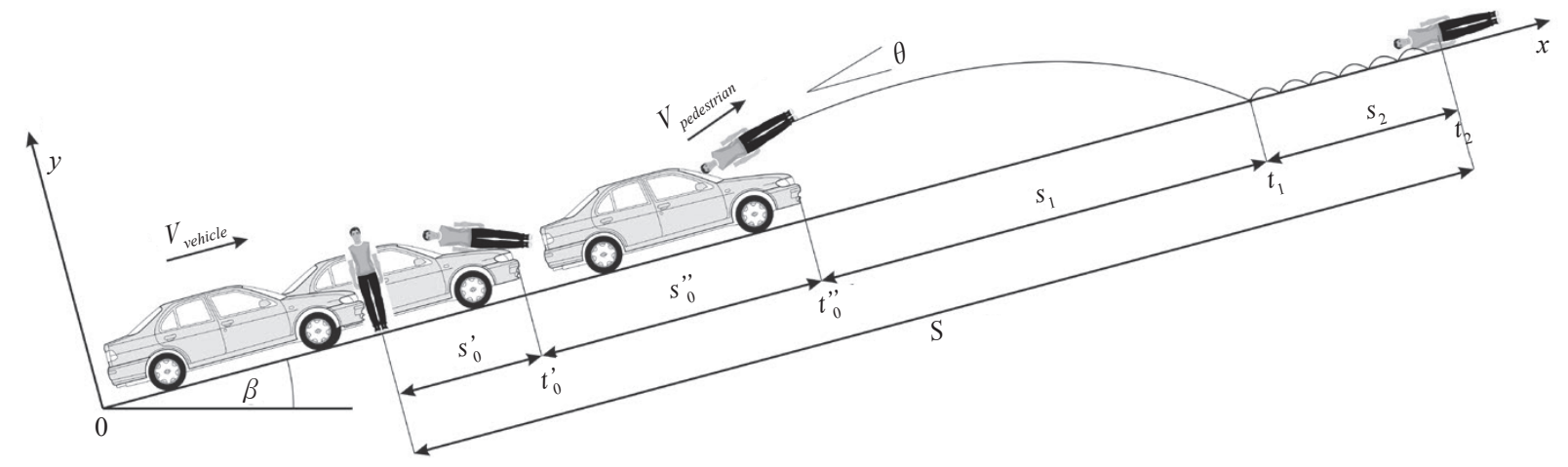

Figure 1-Pedestrian throw distance graph [9, 13] 
It often happens that a poor accident investigation does not provide enough facts that would reliably answer numerous questions put before the transportation-technology expert witness.

This paper defines the pedestrian throw distance prediction model using data (attributes) obtained through subsequent evidence analyses. The attributes used in the model are: vehicle shape, vehicle height, vehicle ride height, position of the greatest damage to the vehicle, if there was driver braking reaction or not, if there were visible skid marks, vehicle damage intensity, pedestrian height, pedestrian centre-of-gravity height, pedestrian-vehicle impact position, angle between vehicle and pedestrian velocity vectors, type of vehicle-pedestrian collision, as well as relations between various parameters.

\section{PEDESTRIAN THROW DISTANCE}

Longitudinal throw distance $(S)$ is the most important and most reliable indicator in determining the collision of the vehicle. Burg and Moser [14] stated in their paper that the height and weight of the pedestrians had a negligible impact on the overall distance projection, specifically, on flight and slide distance because of the significant differences in the masses and speed movements of the vehicles and pedestrians, and therefore, kinetic energies of the two participants. However, this impact cannot be determined each time in the real-life traffic accidents. Pedestrian throw distance consists of three parts (phases):

1) $s_{0}$-the distance travelled by the pedestrian on the vehicle,

2) $s_{1}$-the flight distance of the pedestrian's body,

3) $s_{2}$-the sliding distance of the pedestrian's body on the surface (Figure 1).

$S=s_{0}+s_{1}+s_{2}$

Partial parts of distance throw parameter match the characteristics of vehicle-pedestrian collision phases, as explained by Eubanks [10]: contact and carry phase, flight phase, and sliding phase (Figure 1).

As per Soica and Tarulescu [15], the first phase of the vehicle-pedestrian collision can be divided into two sub-phases:

- Sub-phase 1 - from primary impact to pedestrian head/torso contact with the bonnet/windshield;
- Sub-phase 2 - from pedestrian head/torso contact with the bonnet/windshield of the vehicle to separation of the pedestrian body from the vehicle. The second sub-phase can also be called 'carrying-on-the-bonnet phase'.

The primary impact usually occurs with the vehicle bumper, when the pedestrian calves are hit. The exact position of the impact depends on the type and shape of the vehicle body as well as the pedestrian height (whether it is a child or an adult). If the vehicle is wedge-shaped, the pedestrian will be hit in the calf, and then the 'wrap over' phase starts. In this case, during the primary impact, only one part of kinetic energy of the vehicle is transferred onto the pedestrian. If the vehicle is pontoon-shaped, the primary impact involving an adult will occur between the middle of the calf and knee. The exact position depends on the specific vehicle shape and possible vehicle deceleration. At the same time, the kinetic energy that is being transferred from the vehicle to the pedestrian is considerably higher than in the previous case [14].

The flight phase commences at the point of pedestrian's separation from the vehicle, and ends with the start of the sliding phase, i.e. pedestrian's first contact with the ground. The start of the sliding phase in real-life traffic accident can only be determined by the marks left on the road by the pedestrian. By analysing the recorded tests, Burg and Moser concluded that the friction of pedestrian-ground interaction significantly decelerates the pedestrian speed. The flight duration and distance of the pedestrian depend on the pedestrian speed projection from the vehicle, and on the projection angle.

The test analysis showed that the collision velocity of 33 to $49 \mathrm{~km} / \mathrm{h}$ resulted in 0.45 to $0.7 \mathrm{~s}$ flight. During the flight, the estimated pedestrian deceleration is 0.75 to $1.8 \mathrm{~m} / \mathrm{s}^{2}$ [14].

In the flight phase, the body of the pedestrian acts like a body launched with a sloping or horizontal shot. When the vehicle-pedestrian collision occurs below the pedestrian centre of gravity, the body is launched like a sloping shot. If the impact occurs above pedestrian centre of gravity, the body will fly by the horizontal shot principle.

The sliding phase commences with any part of the body touching the ground and lasts until the pedestrian rest position (pedestrian centre of gravity is the reference point). A short flight can occur during the sliding phase (because of uneven terrain). The 
sliding phase duration depends on the speed of the pedestrian ground interaction, impact angle, and type of road accident.

The analysis of seven collision tests with the same dummy and similar collision velocities, resulted in 2.0 to $5.9 \mathrm{~m}$ sliding distance and 0.71 to $1.24 \mathrm{~s}$ sliding time, which corresponds to an average sliding deceleration of $7.2-8.2 \mathrm{~m} / \mathrm{s}^{2}$. Burg and Moser concluded that, depending on the type of dummy ground impact, various sliding decelerations occur, which leads to different sliding distances at the same collision velocity [14].

Respecting the Newton's second law, the Coulomb friction law, and observing the pedestrian movement through the trajectory of the centre of gravity $[8,9,16]$, which leads to the following equation for pedestrian throw distance:

$S=s_{0}+f_{p} \cdot h+\frac{\left[V_{p}^{\prime} \cdot\left(\cos \theta+f_{p} \cdot \sin \theta\right)\right]^{2}}{2 \cdot g \cdot\left(\sin \alpha+f_{p} \cdot \cos \alpha\right)}$

$V_{p}^{\prime}=\eta \cdot V_{s}^{\prime}=\frac{\eta \cdot V_{s}}{1+\frac{m_{p}}{m_{V}}}$

where:

$\theta$-pedestrian throw angle $\left[{ }^{\circ}\right]$;

$h$-pedestrian throw height [m];

$g$-gravitational acceleration $\left(9.81 \mathrm{~m} / \mathrm{s}^{2}\right)$;

$f_{p}$-pedestrian ground friction coefficient;

$V_{s}$-vehicle impact speed;

$V_{s}^{\prime}$-vehicle separation speed;

$V_{p}^{\prime}$-pedestrian separation speed;

$\eta$-coefficient that equals vehicle speed, pedestrian speed and vehicle post-impact speed.

Results of Equations 1-3 show that there is also a physical connection between the vehicle speed parameters at the impact and the pedestrian throw distance. However, it is hard to determine the accurate values of certain parameters, such as, pedestrian throw angle or throw height. The throw distance value is also difficult to ascertain if the exact point of contact and final position of the pedestrian body after vehicle impact are unknown. Because of the aforementioned deficiencies, applying Equations 1-3 to the analysis of the actual traffic accidents is not possible. As a result, an idea was created to determine the pedestrian throw distance on the basis of data available after every traffic accident, as shown in Equations 5 and 6.

\section{METHOD}

The World Health Organisation (WHO) graded the severity of injuries so that, based on these qualitative and partially quantitative indicators, the previous examples of professional practice could be used, and for the purpose of establishing certain dependencies, and specifying the values of impact factors. Internationally, the practice for this approach would be the use of AIS (Abbreviated Injury Scale) value, formed as ordinal scale, which was used for the following classification:

0 - no determined injuries;

1 - minor injury;

2 - moderate injury;

3 - serious injury, but not life-threatening;

4 - severe injury, life-threatening, but with the pedestrian likely to survive;

5 - critical life-threatening injuries, without emergency intervention the pedestrian is not likely to survive;

6 - instant death [17].

The most common injuries in traffic accidents involving a pedestrian are: head, pelvis, chest, and leg injuries. Separate AIS values are established for the injuries of the abovementioned human body parts, with a detailed description of the type of injury. Without the pedestrian throw distance parameter, it is difficult to determine the vehicle speed. However, the purpose of this paper is to determine the throw distance parameter in a different way in order to apply any one of the models for determination of the forward vehicle speed. In their paper, Glynn and Wood [18] showed the impact of damage on the pedestrian speed. However, they focused on the location of the vehicle damage - distance from the front and side of the vehicle. Another way for determining the forward vehicle speed at the point of impact with the pedestrian is the position of the vehicle damage, i.e. the pedestrian head impact on the bonnet and/or windshield, as shown in Figure 2 [13].

As per AIS value scale, the existing vehicle speed determination, and other studies, the idea was to analyse the vehicle damage differently, and to instil the detailed damage report to ordinal scale, in 1 to 15 intervals. Since the pedestrian injuries were graded on a scale from 0 to 6 , following the severity of injuries from minor to deadly, the idea is to categorise the vehicle damage at the point of collision with the pedestrian, according to its intensities. The numerical value that would indicate the damage intensities is therefore obtained from a detailed vehicle damage report. Table 2 shows the damages chronologically, from minor to major, as well as their codes.

Figures $3 a$ and $3 b$ show extreme situations, i.e. damages that match numerical codes 1 and 15 . 


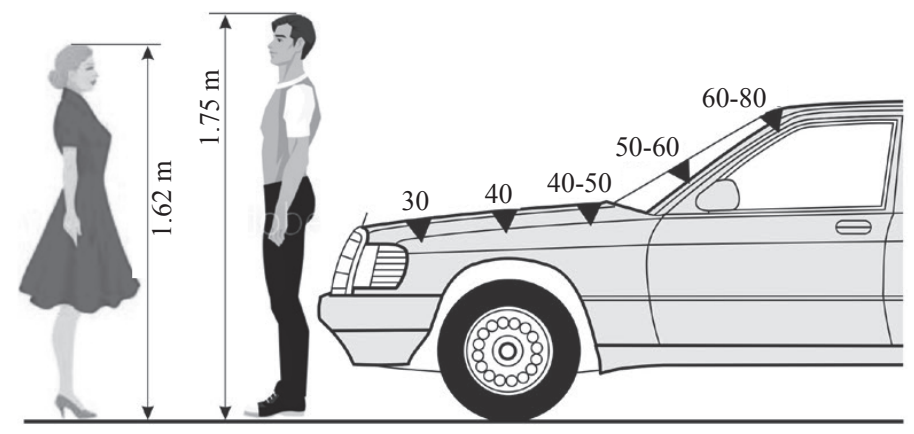

Figure 2-Dependence of head collision point and vehicle speed [13]

Table 2 - Vehicle damage categories, on impact with pedestrian

\begin{tabular}{||c|l||}
\hline $\begin{array}{c}\text { Numerical } \\
\text { damage code }\end{array}$ & \multicolumn{1}{|c||}{ Detailed damage report } \\
\hline \hline 1 & No visible damages, except dust outline \\
\hline 2 & $\begin{array}{l}\text { Minor damages at the front - bent plastic, registration plate, cracked headlight glass, scratches on the side of } \\
\text { the vehicle }\end{array}$ \\
\hline 3 & $\begin{array}{l}\text { Major damages at the front - broken headlight glass, loose parts, some windshield chips, broken rear-view } \\
\text { mirror }\end{array}$ \\
\hline 4 & Minor dents on the bonnet or front bumper, at the front in the form of dents, without damage to the front \\
\hline 5 & Minor dents on the bonnet or front bumper, at the front in the form of dents, including damage to the front \\
\hline 6 & Minor dents at the back of the bonnet, including damage to the front \\
\hline 7 & Minor windshield cracks, including damages to the front - bonnet not damaged \\
\hline 8 & Minor windshield cracks, including damage to the front, bonnet damaged \\
\hline 9 & Major dents on the bonnet or front bumper, at the front in the form of dents, including damage to the front \\
\hline 10 & Major dents at the back of the bonnet, including damage to the front \\
\hline 11 & Major windshield cracks, including damage to the front \\
\hline 12 & Major bonnet dents and major windshield cracks, including damage to the front \\
\hline 13 & Major dents at the back of the bonnet and completely broken windshield, including damage to the front \\
\hline 14 & Damaged windshield - broken, and damaged roof with windshield \\
\hline 15 & Completely wrecked vehicle - completely deformed bonnet, roof, windshield shuttered and out \\
\hline
\end{tabular}

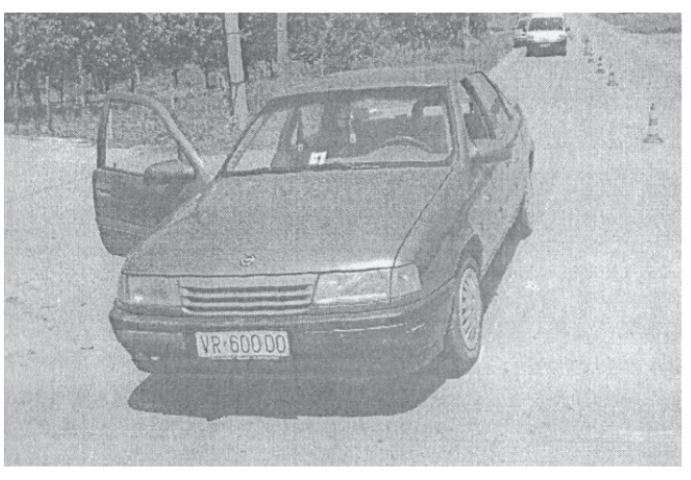

a) Matching numerical code 1

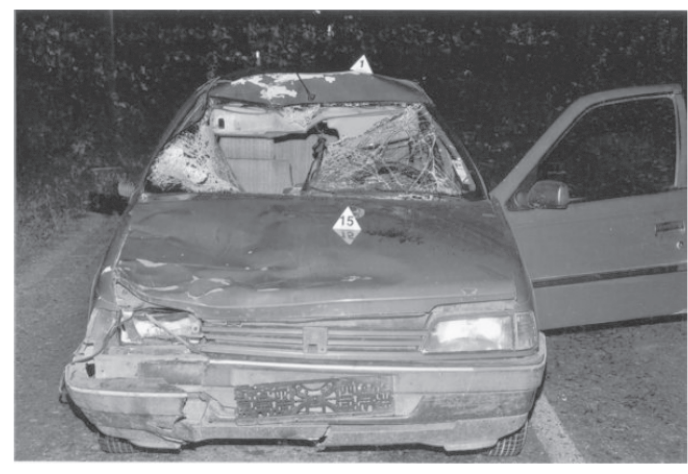

b) Matching numerical code 15

Figure 3 - Vehicle damage

Source: Expert Witness Association of the Traffic Department of the Faculty of Technical Sciences 


\subsection{Research area}

Vehicle and dummy tests were used to demonstrate the impact of vehicle damage on the throw distance when in contact with the pedestrian, and consequently, the speed of the vehicle at impact.

The performed tests database is part of the PC Crash software package [19]. Each test measured the position of the dummy pre-impact, position of the dummy, car and other traces after simulation. Every detail was photographed, including the vehicle before and after simulation (Figures $4 a$ and $4 b$ ), in order to see the damages distinctly. The entire test process was mostly recorded by camera.

Numerous parameters for further analysis could be confidently established. Unfortunately, dummy models are not known in all crash tests so, as a result, the dummy height and centre of gravity cannot be determined.

The analysis of traffic accidents involving pedestrians was done in parallel with the crash tests. They were subject to expert witnessing of the Expert Witness Association of the Traffic Department of the Faculty of Technical Sciences at the University of Novi Sad over the period of 20 years. They were real-life situations, which happened on the territory of Serbia, Montenegro or Bosnia and Herzegovina. Over 300 traffic accidents related to vehicle-pedestrian collision were analysed in that period. However, not all these situations were reinforced by relevant data for the analysis. In most cases the pedestrian height was unknown, and as a result, the centre of gravity. Also, the pedestrian throw distance was questionable in a number of incidents because of the unidentified place of contact, i.e. final position of the pedestrian. As a result, 171 incidents were isolated for further analysis so that all elements needed for the analysis could be

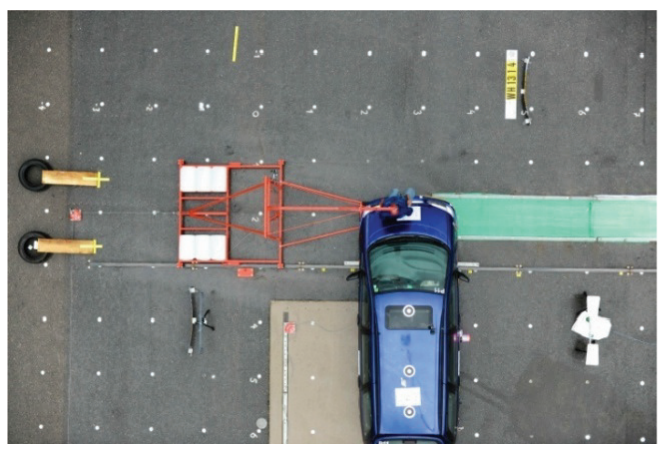

a) Moment of impact determined. Unfortunately, none of the data contained the pedestrian masses so this parameter was not taken into account during analysis. Accordingly, the vehicle masses were not considered either because there was no record that the vehicle carried a cargo, or it was empty, how many passengers were carried, etc.

The vehicle-pedestrian frontal impact was included in this research. The incidents with abrupt vehicle braking pre-impact and delayed driver braking were also considered. As for the vehicle shape, the wedge-shaped and pontoon-shaped vehicles were considered because a fewer number of incidents involved the box-shaped vehicles. The majority of independent parameters can be defined afterwards in case they were not determined in the accident investigation. For example, vehicle damages can be described days after the investigation and thus, categorised. The same can be said for the position of the greatest damage to the vehicle, pedestrian height, etc. as they can be measured subsequently.

\section{PEDESTRIAN THROW DISTANCE MODEL}

When defining a model for prediction of pedestrian body throw distance, a database obtained from the investigation work done by the Expert Witness Association of the Faculty of Technical Sciences, was used. The model was tested on the data obtained from the traffic accident simulations as part of PC Crash software package.

The Exploratory Factor Analysis is used first in order to identify the most important dimensions of data quality. By applying the factor analyses, identification of the common characteristics of multiple attributes is performed, as well as a reduction of the number of attributes in the analyses if there

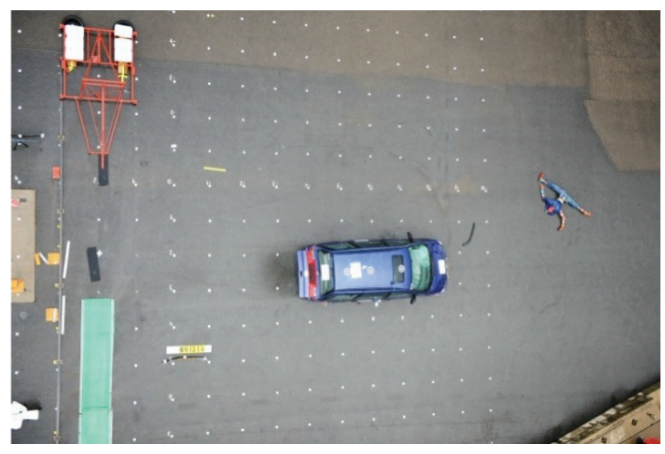

b) Final moment

Figure 4-Crash test example [19] 


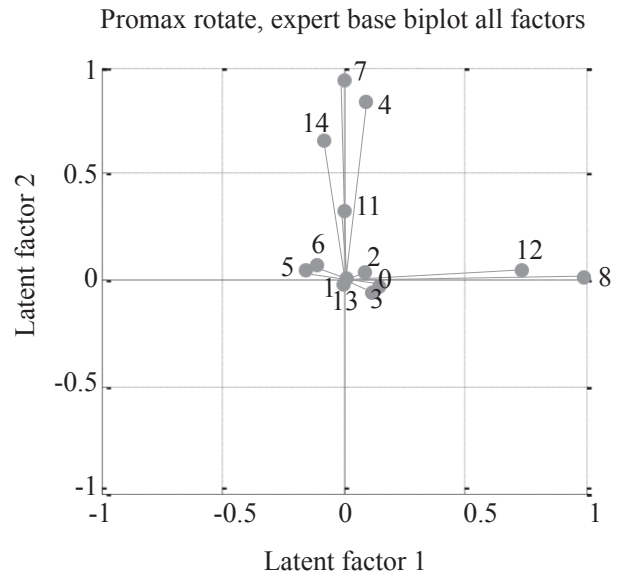

a)

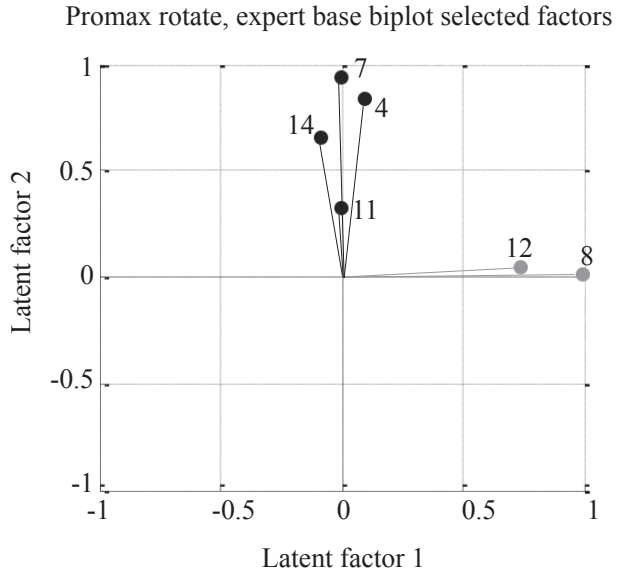

b)

Figure 5 - a) Factor analysis, b) Isolated latent factors

(1-vehicle shape, 2-vehicle height, 3 -vehicle ride height, 4 - greatest damage position, 5 - braking reaction, 6 - are there any skid marks, 7 -vehicle damage intensity, 8 - pedestrian height, 9 - pedestrian centre of gravity, 10 -vehicle-pedestrian collision position, 11 -vehicle-pedestrian collision type, 12 - pedestrian height and vehicle ride height ratio, 13 -angle between vehicle and pedestrian velocity vector, 14 - pedestrian throw distance)

are too many. Figure $5 a$ shows the Promax rotation of all attributes from the Expert base for two factors. Figure $5 b$ shows isolated factors from Figure $5 a$. They are the best representatives of two latent groups of factors.

A conclusion can be drawn that the latent factors are the pedestrian height and the ratio between the pedestrian and vehicle ride height on the one hand. These factors can be described as the physical measurements. On the other hand, the second latent factors are the pedestrian throw distance, vehicle damage intensity, greatest damage position and vehicle shape. These factors can be described as the dynamic elements of the vehicle-pedestrian collision (Figure $5 b$ ). Therefore, these attributes are further analysed in the paper and shown in Table 3, along with their description and values.

In order to determine the relation between two or more attributes, it is first necessary to determine their correlation. The most used parameter correlation measurement of two attributes is Pearson's coefficient correlation calculation technique ${ }^{\circledR}$. The value of this coefficient is a measure of the strength of the linear relationship between attributes. According to Ratner [20] the linear relationship between variables is indicated, if the absolute value of correlation coefficient is higher than 0.3.

Because of different kinematics of pedestrian post-impact body movement upon full and partial vehicle-pedestrian contact, the situations are further distinguished. The cases with full frontal impact between vehicles were analysed separately from the cases where the contact was of inbound, outbound, or partial character.

By analysing the correlation coefficient between certain parameters, a strong and moderate positive correlation is evident between the pedestrian throw distance and the damage intensity and the greatest damage position (Table 4). The same conclusion is drawn from separate analyses of the cases with full frontal vehicle-pedestrian collision and partial vehicle-pedestrian collision, with the vehicle ride height occurring as the weak negative correlation with the pedestrian throw distance at partial impacts.

After calculating the Correlation matrix, modelling was considered next. The pedestrian throw distance was identified as the response variable whereas the elements that indicated a large correlation with the pedestrian throw distance appeared as predictive variables. These are vehicle damage intensity and the greatest vehicle damage position, as well as possible relations between parameters. Linear, possibly polynomial models were explored during modelling. The research explored the most adequate regression equation that would predict the response variable in the best possible way. Multiple regression coefficients $(a, b, c, \ldots)$ were determined with the least square method [21].

$y=a+b \cdot x_{1}+c \cdot x_{2}+d \cdot x_{3} \cdots$

When modelling, the attention was drawn to significance of the predictor variables in the model using coefficient of determination $\left(\mathrm{R}^{2}\right.$ and $\mathrm{R}^{2}$-adj) 
Table 3 - Defined values of variables during research

\begin{tabular}{|c|c|c|c|}
\hline Index & Variable & Description & Value \\
\hline \multirow{7}{*}{$O_{K}$} & \multirow{7}{*}{ Body shape } & saloon & 1 \\
\hline & & coupe & 2 \\
\hline & & hatchback & 3 \\
\hline & & monovolume & 4 \\
\hline & & station wagon & 5 \\
\hline & & jeep & 6 \\
\hline & & pick-up & 7 \\
\hline$V_{P V}$ & Vehicle ride height & 1 & $\mathrm{~m}$ \\
\hline \multirow{16}{*}{$V_{O}$} & \multirow{16}{*}{ Greatest damage position } & No damage & 0 \\
\hline & & $0.1-0.2 \mathrm{~m}$ & 1 \\
\hline & & $0.2-0.3 \mathrm{~m}$ & 2 \\
\hline & & $0.3-0.4 \mathrm{~m}$ & 3 \\
\hline & & $0.4-0.5 \mathrm{~m}$ & 4 \\
\hline & & $0.5-0.6 \mathrm{~m}$ & 5 \\
\hline & & $0.6-0.7 \mathrm{~m}$ & 6 \\
\hline & & $0.7-0.8 \mathrm{~m}$ & 7 \\
\hline & & $0.8-0.9 \mathrm{~m}$ & 8 \\
\hline & & $0.9-1.0 \mathrm{~m}$ & 9 \\
\hline & & $1.0-1.1 \mathrm{~m}$ & 10 \\
\hline & & $1.1-1.2 \mathrm{~m}$ & 11 \\
\hline & & $1.2-1.3 \mathrm{~m}$ & 12 \\
\hline & & $1.3-1.4 \mathrm{~m}$ & 13 \\
\hline & & $1.4-1.5 \mathrm{~m}$ & 14 \\
\hline & & $1.5-1.6 \mathrm{~m}$ & 15 \\
\hline$I_{O}$ & Vehicle damage intensity & Described previously & 1 \\
\hline$V_{P}$ & Pedestrian height & 1 & $\mathrm{~m}$ \\
\hline$O_{V}$ & Ratio between the pedestrian and vehicle ride height & 1 & 1 \\
\hline$S$ & Pedestrian throw distance & 1 & $\mathrm{~m}$ \\
\hline
\end{tabular}

Table 4 - Correlation coefficient between parameters

\begin{tabular}{|c|c|c|c|c|c|c|c|c|c|c|c|c|c|c|}
\hline & \multicolumn{7}{|c|}{ Full vehicle-pedestrian collision } & \multicolumn{7}{|c|}{ Partial vehicle-pedestrian collision } \\
\hline & $O_{K}$ & $V_{P V}$ & $V_{O}$ & $I_{O}$ & $V_{P}$ & $O_{V}$ & $S$ & $O_{K}$ & $V_{P V}$ & $V_{O}$ & $I_{O}$ & $V_{P}$ & $O_{V}$ & $S$ \\
\hline$O_{K}$ & & 0.120 & -0.022 & 0.004 & 0.055 & -0.013 & -0.026 & & 0.114 & 0.064 & 0.026 & -0.266 & -0.290 & 0.129 \\
\hline$V_{P V}$ & & & 0.006 & 0.001 & 0.133 & -0.620 & 0.046 & & & 0.003 & -0.051 & 0.040 & -0.553 & -0.300 \\
\hline$V_{O}$ & & & & 0.769 & 0.395 & 0.299 & 0.552 & & & & 0.753 & 0.261 & 0.211 & 0.578 \\
\hline$I_{O}$ & & & & & 0.341 & 0.253 & 0.680 & & & & & 0.092 & 0.100 & 0.612 \\
\hline$V_{P}$ & & & & & & 0.690 & 0.097 & & & & & & 0.809 & -0.032 \\
\hline$O_{V}$ & & & & & & & 0.038 & & & & & & & 0.151 \\
\hline$S$ & & & & & & & & & & & & & & \\
\hline
\end{tabular}

$O_{K}$-vehicle body shape; $V_{P V}$-vehicle ride height; $V_{O}$ - greatest damage position; $I_{O}$ - vehicle damage intensity; $V_{P}-$ pedestrian height; $O_{V}$-pedestrian-vehicle height ratio; $S$ - pedestrian throw distance.

and p-value. Statistical significance of the predictor variable gives information whether the predictor variable can be disregarded or not, i.e. the p-value gives the probability of error if the regression coefficient that stands next to the attribute in the model is equal to zero. A model ascertained through 'step' function in the program $\mathrm{R}$ package best describes the throw distance as the response variable on the basis of chosen predictor variables.

The models for throw distances at full and partial vehicle-pedestrian collision are shown in Table 5 together with the following equations (models). 
Table 5 - Regression analysis results

\begin{tabular}{||l|c|c|c|c|c||}
\hline & \multicolumn{2}{|c|}{ Statistical significance of variables } & \multicolumn{2}{c||}{$\mathrm{R}^{2}$-adj } & $\mathrm{p}$-value \\
\hline \hline Pedestrian throw distance - full impact & ${ }^{* * *}\left(V_{o} \cdot I_{o}\right)^{2}$ & ${ }^{* *} I_{o}$ & ${ }^{* * *}\left(V_{o} \cdot I_{o}\right)$ & 0.542 & $2.2 \mathrm{e}-16$ \\
\hline Pedestrian throw distance - partial impact & ${ }^{* * *}\left(V_{o} \cdot I_{o}\right)^{2}$ & ${ }^{*} V_{o}$ & ${ }^{* *}\left(\frac{10 \cdot V_{O}}{V_{P V}}\right)$ & 0.566 & $3.84 \mathrm{e}-10$ \\
\hline
\end{tabular}

$V_{P_{* * * *}}$-vehicle ride height; $V_{O}$ - greatest damage position; $I_{O}$-vehicle damage intensity; $S$-pedestrian throw distance.

$0{ }^{* * * *} 0.001$ : very strong significance

$0.001^{* * *} 0.01$ : strong significance

$0.01^{* *} 0.05$ : significant

The model is considered better if it has $\mathrm{R}^{2}$-adj close to one. The model for determination of the pedestrian throw distance at full impact is defined as per database obtained from the investigation work done by the Expert Witness Association of the Faculty of Technical Sciences, which shows that the best result is as follows:

$S=8.19+1.26 \cdot 10^{-3} \cdot\left(V_{O} \cdot I_{O}\right)^{2}+2.80 \cdot I_{O}-0.32 \cdot V_{O} \cdot I_{O}$

The model for determination of the pedestrian throw distance at partial impact is defined as per database obtained from the investigation work done by the Expert Witness Association of the Faculty of Technical Sciences, which shows that the best result is as follows:

$$
S=4.10+4.75 \cdot 10^{-4} \cdot\left(V_{O} \cdot I_{O}\right)^{2}+3.17 \cdot \frac{V_{O}}{V_{P V}}-3.67 \cdot V_{O}
$$

The residual plot does not show any regularity, seasonality or heteroscedasticity, i.e. the residuals are distributed as a zero mean white noise (Figure 6).

The models were obtained as per database that was collected from the investigation work done by the expert witnessing of the Expert Witness Association of the Faculty of Technical Sciences (FTS). Testing of the model for prediction of

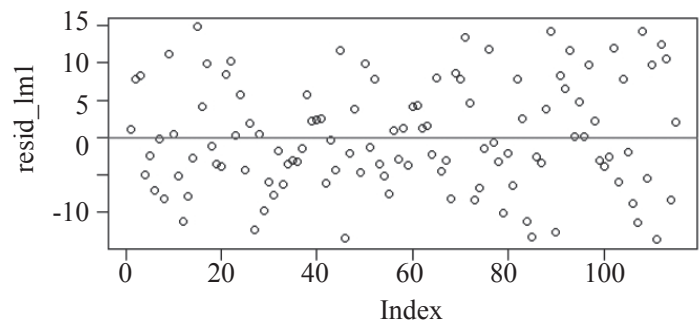

a) Full impact model pedestrian throw distance at full vehicle impact was done as per database obtained from vehicle-dummy crash tests. However, the model for partial vehicle-pedestrian collision cannot be tested because the tests for this type of impact have not been performed.

In order to compare the data in the abovementioned two databases and to test the obtained formulae, t-test between means of the corresponding attributes (predictor variables) needs to be performed.

However, before performing t-test, it is necessary to exclude from the database the cases where the damage intensity parameter is less than 6 , and the greatest damage point below position 7 . The reason for this is that, while performing crash tests, the vehicles reached higher speeds and thus sustained significant damages. The simulations with lower speed and minor damages to the vehicles were not performed. The obtained t-test results are shown in Table 6.

As per performed t-test, the conclusion can be drawn that the data in the abovementioned two databases are comparable. Therefore, the model for the determination of the pedestrian throw distance can be tested, and the results are shown in Table 7.

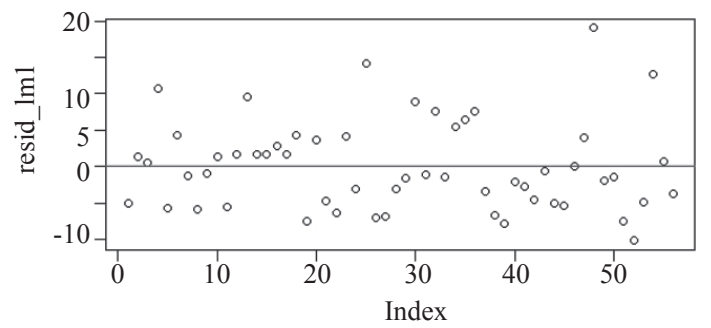

b) Partial impact model

Figure 6-Residuals

Table 6-T-test results

\begin{tabular}{||c|l|c|c|c||}
\hline No. & \multicolumn{1}{|c|}{ Parameter } & $\begin{array}{c}\text { Mean FTS database } \\
\text { value }\end{array}$ & $\begin{array}{c}\text { Mean value of crash } \\
\text { tests database }\end{array}$ & p-value \\
\hline \hline 1 & Vehicle damage intensity & 11.71 & 11.86 & 0.761 \\
\hline 2 & Greatest vehicle damage position & 11.51 & 11.63 & 0.788 \\
\hline 3 & Pedestrian throw distance & 22.86 & 25.44 & 0.473 \\
\hline
\end{tabular}


Saulić N, Papić Z, Ovcin Z. Pedestrian Throw Distance Prediction from Vehicle Damage Intensity

Table 7 - Testing the model for pedestrian throw distance prediction [4, 14, 22, 23]

\begin{tabular}{||c|c|c|c|c|c|c|c|c|c||}
\hline \multirow{2}{*}{$V_{O}$} & \multirow{2}{*}{$I_{O}$} & \multirow{2}{*}{$S^{\text {mea }}[\mathrm{m}]$} & \multirow{2}{*}{$S^{\text {mod }}[\mathrm{m}]$} & \multicolumn{2}{|c|}{$\Delta S$} & $\begin{array}{c}V_{S}^{\text {mea }} \\
{[\mathrm{km} / \mathrm{h}]}\end{array}$ & $\begin{array}{c}V_{S}^{\text {Barzeley }} \\
{[\mathrm{km} / \mathrm{h}]}\end{array}$ & $\begin{array}{c}V_{S}^{\text {Stcher. }} \\
{[\mathrm{km} / \mathrm{h}]}\end{array}$ & $\begin{array}{c}V_{S}^{\text {Moser }} \\
{[\mathrm{km} / \mathrm{h}]}\end{array}$ \\
\hline \hline 12 & 11 & 11.7 & 18.71 & 7.01 & 59.87 & 54.0 & 50.7 & 52.8 & 52.9 \\
\hline 9 & 10 & 31.2 & 17.58 & -12.42 & -41.40 & 50.0 & 48.9 & 51.1 & 51.1 \\
\hline 10 & 8 & 16.2 & 13.04 & -3.46 & -20.96 & 37.4 & 40.8 & 43.4 & 43.1 \\
\hline 10 & 8 & 14.6 & 13.04 & -2.26 & -14.76 & 37.4 & 40.8 & 43.4 & 43.1 \\
\hline 10 & 8 & 16.0 & 13.04 & -3.46 & -20.96 & 37.4 & 40.8 & 43.4 & 43.1 \\
\hline 11 & 11 & 15.6 & 18.71 & 1.91 & 11.38 & 37.4 & 50.7 & 52.9 & 52.9 \\
\hline 13 & 13 & 28.8 & 26.51 & -2.29 & -7.94 & 55.0 & 62.3 & 63.8 & 64.3 \\
\hline 11 & 8 & 15.1 & 12.18 & -2.92 & -19.35 & 46.0 & 39.1 & 41.8 & 41.4 \\
\hline 14 & 15 & 46.0 & 38.60 & -7.10 & -15.54 & 80.0 & 77.3 & 78.0 & 79.0 \\
\hline 14 & 14 & 47.0 & 33.11 & -13.59 & -29.10 & 70.0 & 70.8 & 71.9 & 72.6 \\
\hline 14 & 15 & 60.0 & 38.60 & -21.40 & -35.67 & 89.0 & 77.3 & 78.0 & 79.0 \\
\hline 7 & 6 & 14.5 & 13.76 & -1.24 & -8.29 & 43.0 & 42.1 & 44.7 & 44.4 \\
\hline 13 & 9 & 19.0 & 13.20 & -5.30 & -28.66 & 44.1 & 41.1 & 43.7 & 43.4 \\
\hline 9 & 8 & 12.5 & 14.07 & 1.07 & 8.21 & 42.5 & 42.7 & 45.2 & 45.0 \\
\hline 9 & 10 & 12.5 & 17.58 & 4.98 & 39.53 & 42.5 & 48.9 & 51.1 & 51.1 \\
\hline 11 & 12 & 21.1 & 21.50 & 0.40 & 1.90 & 55.9 & 55.1 & 57.0 & 57.2 \\
\hline 11 & 12 & 30.5 & 21.50 & -8.50 & -28.33 & 55.1 & 55.1 & 57.0 & 57.2 \\
\hline 13 & 8 & 11.7 & 10.94 & -0.76 & -6.53 & 42.1 & 36.6 & 39.3 & 38.9 \\
\hline 13 & 9 & 14.1 & 13.20 & -1.30 & -8.98 & 43.5 & 41.1 & 43.7 & 43.4 \\
\hline \hline
\end{tabular}

$V_{O}$-greatest damage position; $I_{O}$ - vehicle damage intensity - greatest vehicle damage. $S^{\text {mea }}$ - pedestrian throw distance, measured value; $S^{\text {mod }}$ - pedestrian throw distance, modelled value; $\Delta S$-relative error of throw distance; $V_{S}^{\text {mea }}$ - vehicle impact speed, measured value;

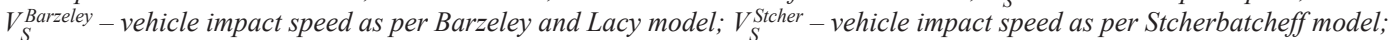

$V_{S}^{M o s e r}$ - vehicle impact speed as per Moser and Burg model.

The analysis of the model testing results established that the average error in the prediction of throw error was around $5.3 \mathrm{~m}$, i.e. around $21 \%$ in comparison to the actual measured value of the throw distance. In 14 out of 19 cases, the modelled value was lower than the realisable value. Large differences between the realisable and modelled values should be accounted for by the fact that the traffic accident simulations include dummies that are foremost lighter; have less resistance in comparison to the pedestrian body and lower friction coefficient in the sliding phase.

Three models for determining the forward vehicle speed at the point of contact with the pedestrian were applied, as developed by Barzeley and Lacy [22], Stcherbatcheff [4, 23], Burg and Moser [14]. The results obtained from the model described in this paper were included instead of the measured pedestrian throw distances. The measured vehicle speeds in these cases do not deviate much from the real values applied by the vehicles in the crash tests. By applying any one of the three models, the average error is less than $10 \%$. There are also certain models that define the minimum and maximum values of the vehicle speed, which were developed by Wood [7] and Searle [3, 25, 26]. By applying these models, but with inclusion of the throw distance attained from Equation 5, exact predictions of the vehicle speed are obtained.

\section{CONCLUSION}

Longitudinal throw distance $(S)$ is the most important and most reliable indicator in determining the collision velocity of the vehicle. The vehicle speed at the impact with the pedestrian is one of the parameters that need to be ascertained when determining the circumstances of the respective accident. The vehicle speed can be determined from the skid marks, by analysing recorded videos (if the respective accident was recorded by one of the nearby surveillance cameras) or by analysing the tachograph cards taken from the vehicle. Since there are rare situations where some of these conditions are met, 
the vehicle impact speed is often determined from the empirical model. All thus far known models for the measurement of this element are based on the pedestrian throw distance identification (Table 1).

In order to identify the throw distance parameter it is necessary to know the vehicle-pedestrian contact point and the position of the pedestrian post-accident. If one of these two facts cannot be determined, neither can the throw distance. Therefore, none of the empirical formulae for determination of the forward vehicle speed can be used.

The purpose of this paper is to determine whether the vehicle damage intensity in collision with the pedestrian impacts the pedestrian throw distance. The recorded damage description is set in the ordinal scale from 1 to 15 (Table $3 a$ ). A real advantage of this parameter is that it does not have to be defined by the investigating team immediately but instead, it can be subsequently determined by analysing the photographs from the investigation files.

The data used in this paper are obtained from the investigation work done by the Expert witnessing of the Expert Witness Association of the Traffic Department of the Faculty of Technical Sciences at the University of Novi Sad, as well as data obtained from the performed tests with vehicles and dummies. All the necessary measurements were performed within each test (position of the dummy pre-impact, as well as position of the dummy, vehicle and other traces after simulation, vehicle speed, etc.). Almost all simulations were recorded, and all the details were photographed which were therefore the laboratory studies. The vehicle-dummy impact simulation is in the database as part of the PC Crash software package.

The research included the frontal vehicle-pedestrian collisions with full vehicle-pedestrian collisions analysed separately from the partial vehicle-pedestrian collisions.

The factor analysis with two factors of attributes showed that one group of latent factors consists of pedestrian throw distance, vehicle damage intensity set in the ordinal scale, the greatest vehicle damage point and the vehicle body shape.

The correlation coefficient determined that there is a significant connection between the pedestrian throw distance element and the vehicle damage intensity element, and the greatest damage point, whether it is a question of full frontal or partial vehicle-pedestrian collision.

The paper showed the models for prediction of the pedestrian throw distance for both mentioned collision types. The model for pedestrian throw distance at full collision with the vehicle was tested in crash tests that are part of the PC Crash software package. The results obtained from the modelling on average differ from the actual throw distance by about $21 \%$.

However, by applying the models for determining the vehicle speed, as defined by Barzeley and Lacy [22], Stcherbatcheff [4, 24], Burg and Moser [14], the prediction, which differs from the realisable vehicle speed by less than $10 \%$, is determined.

On the basis of all the above, this paper has shown that the parameters for the throw distance could be obtained from the damage to the vehicle that collided with the pedestrian, and then by applying some of the models for determination of the vehicle speed, one can obtain satisfactory results.

Therefore, in cases where the pedestrian throw distance is undetermined, and there are no alternative methods for the measurement of vehicle speed, the model described in this paper can be applied.

\section{MSc NENAD SAULIĆ}

E-mail: nenadsaulic@gmail.com,n.saulic@uns.ac.rs Dr ZORAN PAPIĆ ${ }^{1}$

E-mail: njele@uns.ac rs

Dr ZORAN OVCIN ${ }^{1}$

E-mail: zovcin@uns.ac.rs

${ }^{1}$ Universitet u Novom Sadu, Fakultet tehničkih nauka

Trg Dositeja Obradovića 6, 21000 Novi Sad, Srbija

\section{PREDIKCIJA DALJINE ODBAČAJA PEŠAKA NA OSNOVU INTEZITETA OŠTEĆENJA VOZILA}

\section{REZIME}

Prilikom analize saobraćajnih nezgoda, jedna od bitnih stavki na koje je potrebno dati odgovor jeste brzina kretanja vozila u trenutku kontakta. Ukoliko saobraćajna nezgoda nije snimljena, na kolovozu nisu ostali tragovi kočenja ili ne postoji tahografski uređaj na vozilu, ovaj parametar se utvrđuje na osnovu empirijskih modela. Svi empirijski modeli za određivanje brzine kretanja vozila se baziraju na daljini odbačaja pešaka, koji nije uvek poznat zbog nepoznavanja mesta naleta vozila na pešaka ili krajnje pozicije pešaka nakon nezgode. U ovom radu je deskriptivni opis oštećenja vozila pretočen u ordinalnu skalu i utvrđen je model predikcije daljine odbačaja pešaka na osnovu ovako definisanog oštećenja vozila. Ukoliko se poseduju fotografije sa uviđaja može se izvršiti i klasifikacija oštećenja i primenom dobijenog modela predvideti daljina odbačaja pešaka. A zatim primenom nekog empirijskog modela, može se definisati i brzina kretanja vozila u trenutku naleta na pešaka. Prilikom istraživanja formirane su dve baze podataka, jedna na osnovu realnih saobraćajnih nezgoda, koja su bila predmet veštačenja Komisije veštaka sa Fakulteta tehničkih 
nauka. Druga baza je formirana na osnovu odrađenih simulacija saobraćajnih nezgoda, koje se nalaze u okviru programskog paketa PC Crash.

\section{KLJUČNE REČI}

saobraćajne nezgode sa pešacima; daljina odbačaja; oštećenje vozila; brzina kretanja vozila;

\section{REFERENCES}

[1] Gábor M. Gépjármüszakértés. Budapest: Maróti Könyvkereskedés és Könyvkiadó Kft.; 2004.

[2] Limpert R. Brake Design and Safety. United States of America: Society 01'Autonlohve Engineers; 1999.

[3] Searle JA, Searle A. The Trajectories of Pedestrians, Motorcycles, Motorcyclists, etc. Following a Road Accident. SAE Technical Paper 831622; 1983; p. 277-80. Available from: doi:10.4271/831622

[4] Stcherbatcheff G, Tarriere C, Duclos P, Fayon A. Simulation of Collisions Between Pedestrians and Vehicles Using Adult and Child Dummies. SAE Technical Paper 751167; 1975. p. 33. Available from: doi: $10.4271 / 751167$

[5] Simms CK, Wood DP. Confidence limits for impact speed estimation from pedestrian projection distance. International Journal of Crashworthiness. 2004;9(2): 219-28.

[6] Wood DP, Simms CK, Walsh DG. Vehicle - pedestrian collisions : validated models for pedestrian impact and projection. Proceedings of the Institution of Mechanical Engineers Part D Journal of Automobile Engineering. 2005;219(2): 183-195.

[7] Fugger TF, Randles BC, Wobrock JL, Eubanks JJ. Pedestrian Throw Kinematics in Forward Projection Collisions. SAE 2002 World Congress \& Exhibition. Available from: doi:10.4271/2002-01-0019

[8] Han I, Brach RM. Throw Model for Frontal Pedestrian Collisions. SAE Technical Paper 2001-01-0898; 2001; p. 16.

[9] Batista M. A simple throw model for frontal vehicle-pedestrian collisions. Promet - Traffic\&Transportation. 2008;20(6): 357-68.

[10] Eubanks JJ, Haight WR. Pedestrian involved traffic collision reconstruction methodology. SAE Technical Paper 921591; 1992; p. 37-49.

[11] Cheng Y, Wong K, Tam C, Tam Y, Wong T, Tao C. Validation of pedestrian throw equations by video footage of real life pedestrian/vehicle collisions. Forensic Science International. 2015;257: 409-12.
[12] Wood DP. Application of a pedestrian impact model to the determination of impact speed. SAE Technical Paper 910814; 1991.

[13] Kostić S. Tehnike bezbednosti i kontrole saobraćaja. Faculty of Technical Sciences, University of Novi Sad; 2009. Serbian.

[14] Burg H, Moser A. Handbuch Verkehrsunfall-rekonstruktion. Wiesbaden, Springer Science+Business Media; 2007.

[15] Soica A, Tarelescu S. Impact phase in frontal vehicle-pedestrian collisions. International Journal of Automotive Technology. 2016;17(3): 387-97. Available from: doi:10.1007/s12239-016-0040-y

[16] Zou T, Yu Z, Cai M, Liu J. Analysis and application of relationship between post-braking-distance and throw distance in vehicle-pedestrian accident reconstruction. Forensic Science International. 2011;207(1-3): 135-44.

[17] Lesko MM, Woodford M, White L, O'Brien SJ, Childs C, Lecky FE. Using Abbreviated Injury Scale (AIS) codes to classify Computed Tomography (CT) features in the Marshall System. Medical Research Methodology. 2010;10: 72. Available from: doi:10.1186/1471-2288-10-72.

[18] Glynn C, Wood DP. Pedestrian Speed from Vehicle Damage. 24 EVU Conference, Edinburgh; 2015.

[19] PC-Crash - A Simulation program for Vehicle Accidents, Operating Manual. Version 12.0. Linz, Austria; 2019.

[20] Ratner B. Statistical Modeling and Analysis for Database Marketing: Effective Techniques for Mining Big Data. Chapman \& Hall/CRC; 2003.

[21] Kutner MH, Nachtsheim CJ, Neter J, Li W. Applied Linear Statistical Models. McGraw-Hill/Irwin; 2005. 1415 p.

[22] Barzeley M, Lacy GW. Scientific Automobile Accident Reconstruction. New York, USA: Matthew Bender \& Company Incorporated; 1978.

[23] Bhalla K, Montazemi P, Crandall J, Yang J, Liu X, Dokko $\mathrm{Y}$, et al. Vehicle impact velocity prediction from pedestrian throw distance: Trade-offs between throw formulae, crash simulators, and detailed multi-body modeling. Proceedings of the International IRCOBI Conference on the Biomechanics of Impacts, Munich, Germany; 2002.

[24] Portal RJ, Dias JM. Pedestrian Reconstruction Tools Applied to Pedestrian Accidents in Portugal. Proceedings of the $3^{\text {rd }}$ International Symposium on ESAR "Expert Symposium on Accident Research", Hannover, Germany; 2009; p. 304-14.

[25] Hoxha G, Shala A, Likaj R. Pedestrian crash model for vehicle. International Journal of Civil Engineering and Technology. 2017;8(9): 1093-9. 